\begin{tabular}{|l|l|l|l|l|l|}
\hline J. Tek. Ling & Vol. 12 & No. 2 & Hal. 143 - 152 & Jakarta, Mei 2011 & ISSN 1441-318X \\
\hline
\end{tabular}

\title{
MANFAAT TANAMAN SAGU (Metroxylon sp) DALAM PENYEDIAAN PANGAN DAN DALAM PENGENDALIAN KUALITAS LINGKUNGAN
}

\author{
Bambang Hariyanto \\ Peneliti Utama di Pusat Teknologi Agroindustri BPPT \\ Gedung 2 BPPT, Lt 17. JI MH Thamrin No 8 \\ bambanghar54@yahoo.com
}

\begin{abstract}
Abtract
Sago plants is a source of carbohydrates that can be used as a source of food. With the extruder technology, sago can be made noodles. The purpose of this study is to know the utilization of sago as a provider of food and protecting the environment. Organoleptic testing sago noodles and wheat noodles to the panelists gave results not significantly different. The noodles of sago have a high resistant starch and useful for health. To make use of sago in the manufacture of noodles in the framework of implementation of the Gouverment Regulation (Per Pres) No. 22 th 2009 the need for socialization and support for raw material supplies through sago plantations. When the sago plant is developed it will be beneficial to the absorption of carbon dioxide and maintain the sago air. Sago palm can produced 20 tonnes karbohidrat / ha. Besides sago plants will be able to keep the water around it. Sago leaf has the ability to absorb carbon dioxide $\left(\mathrm{CO}_{2}\right)$ emissions by 240 tons $\mathrm{CO}_{2}$ /ha/th.
\end{abstract}

Key Words : sago,noodle, food, utliization, sustainable

\section{PENDAHULUAN}

\subsection{Latar Belakang}

Perubahan iklim secara global mengakibatkan dampak di semua sektor termasuk produksi pangan. Laporan Kementerian Pertanian tahun 2010 produksi beras secara komulatif mengalamie penurunan dari $5,0 \%$ menjadi $1,7 \%{ }^{11}$. Demikian juga produksi penghasil pangan karbohidrat seperti, jagung dan ubi kayu mengalamie penurunan juga. Dipihak lain kebutuhan akan pangan terutama beras bagi masyarakat Indonesia justru meningkat mencapai 139 kg/kap/th ${ }^{1)}$. Suatu jumlah yang tinggi dan untuk kawasan di Asia merupakan pengkonsumsi beras tertinggi. Upaya untuk mengurangi konsumsi beras terus dilakukan dengan menggalakkan diversifikasi pangan. Keadaan ini telah didukung dengan Peraturan Presiden (PerPres) No 22 Tahun 2009 tentang pemanfaatan bahan baku lokal ${ }^{2)}$.

Namun dalam realita diversifikasi pangan terjadi justru konsumsi terigu terus meningkat setiap tahunnya, dimana konsumsi terigu tahun 2010 sebesar 16 kg/ kapita/th dan tahun mendatang akan terus meningkat ${ }^{1}$. Padahal terigu yang berasal dari tanaman gandum tidak dapat tumbuh di Indonesia dan harus diimpor. Bila hal 
ini terus terjadi maka Indonesia dapat terperangkap dalam jebakan pangan dan sangat tergantung dari produksi gandum di luar negeri.

Selama ini penggunaan terigu di Indonesia hampir $75 \%$ digunakan untuk membuat mie. Oleh sebab itu upaya yang paling strategis adalah membuat miee bahan baku lokal seperti ubi jalar, ubi kayu, jagung dan sagu yang dapat diproduksi di dalam negeri.

Tanaman sagu (Metroxylon sp) banyak dijumpai di daerah rawa dan pinggir sungai di Indonesia dan terpusat di Papua, Maluku, Sulawesi dan Riau. Sejak lama tanaman sagu dikenal sebagai makanan bagi masyarakat Papua maupun Maluku.

Tanaman sagu menyimpan pati sebagai cadangan pangan di bagian batang. Manfaat pati sagu selama ini digunakan sebagai makanan pokok dan bagi masyarakat Papua maupun Maluku dengan nama pepeda. Disamping makanan pokok dari pati sagu dimanfaatkan sebagai makanan kudapan (cemielan) seperti bagea, ongol-ongol, kue bangkit dan sebagainya. Produk lain sebagai campuran untuk soto yang dibuat dalam bentuk soun ${ }^{3)}$.

Waktu berjalan terus dan ketersediaan pangan karbohidrat semakin hari mendapat tantangan akibat perubahan iklim, dimana tanaman semusim seperti padi, gandum dan jagung mengalamie gagal panen. Bahkan ramalan para ahli produksi pangan yang semula tumbuh 5-7 \% pada tahun 2011 ini akan tumbuh hanya $1,7 \%{ }^{1}$.

Perubahan iklim yang akan berpengaruh terhadap produksi pangan terutama karbohidrat di Indonesia ini tidak dapat dibiarkan karena masalah akan semakin serius. Oleh sebab itu penggalian pangan penyedia karbohidrat selain dari biji-bijian seperti beras dan jagung penghasil karbohidrat seperti sagu tidak boleh diremehkan.

Ditinjau dari ketersediaan Iahan sebagai penyedia bahan baku sagu terutama di Papua memiliki areal hampir 1 juta ha ${ }^{4}$.
Disamping itu di daerah lain seperti Maluku, Sulawesi Tenggara, Sulawesi Selatan, Kalimantan Barat dan Riau merupakan sentra tanaman sagu ${ }^{3)}$

Untuk meningkatkan peran sagu maka perlu adanya suatu model percontohan kawasan pengelolaan sagu sebagai bentuk unit usaha dengan didukung proses pengeluaran pati dan kebun sagu yang memadai dan secara ekonomies menguntungkan. Hal ini dimaksudkan untuk memanfaatkan tanaman sagu dan menggerakan perekonomian masyarakat di sekitarnya sehingga dapat memberi peran dalam perekonomiean daerah. Disamping itu perlu dibuat contoh produk makanan dari sagu yang dapat diterima oleh masyarakat bukan pengkonsumsi sagu. Untuk itu pati sagu dibuat dalam bentuk mie. Untuk menjaga pasokan sagu maka dibentuk suatu unit kawasan sebagai pemasok bahan baku sagunya.

\subsection{Tujuan}

Tujuan penelitian ini adalah mempelajari pemanfaatan sagu sebagai penyedia pangan pola penyediaan bahan baku serta agar berkelanjutan.

\section{METODOLOGI}

Metodologi yang digunakan adalah percobaan laboratorium untuk membuat produk mie sagu dan diuji daya terimanya ke panelis. Selanjutnya dianalisis juga model penyediaan sagu sekaligus ditinjau sebagai penyedia pangan dan sebagai penjaga lingkungan. serta dilakukan analisis dengan melihat potensi sagu sebagai model pemasok sagu. Pembuatan produk mie dilakukan dengan metoda ekstruder.

\subsection{Bahan dan Alat}

Bahan yang digunakan adalah pati sagu dan alat yang digunakan adalah mixer, timbangan, pengukus dan ekstruder. 


\subsection{Metoda}

Pembuatan mie sagu dilakukan sebagai berikut: bahan pati sagu ditambah air secukupnya dan diaduk dengan mixer. Setelah tercampur adonan dikukus dan selanjutnya di cetak dengan ekstruder. Hasil cetakan dari ekstruder dalam bentuk mie yang selanjutnya dilakukan pengujian organoleptik. Pengujian organoleptik meliputi atribut warna, tekstur, dan rasa. Penilaian atribut tersebut dilakukan dengan pancaindra dan diberi nilai sebagai berikut : Tidak suka diberi nilai 1 , agak suka nilai 2 , cukup suka diberi nilai 3 , suka nilai 4 dan sangat suka nilainya 5 . Selanjutnya nilai tersebut dihitung dan hal yang sama dilakukan untuk mie terbuat dari terigu sebagai pembanding.

\subsection{Metoda Analisa}

Waktu tanak ditentukan berdasarkan metoda penentuan waktu tanak untuk spaghetti (AACC,1995) seperti yang diuraikan oleh Collado et al 2001 dalam Widaningrum ${ }^{5}$. Sebanyak $5 \mathrm{~g}$ produk dimasak dalam $200 \mathrm{ml}$ akuades mendidih dalam tempat tertutup. Setiap detik sampel dipindahkan dan diletakkan diantara dua gelas arloji kemudian ditekan. Waktu tanak optimum diperoleh pada saat selurh bagian sampel menyerap air dengan sempurna. (tidak terbentuk titik putih)

Kehilangan saat masak (Cooking losses) diuji dengann metoda AACC dalam Collado et al 2001 untuk spaghetti dengan modifikasi dari Purwani6). Sampel 5 gram direbus dimasukkan dalam air mendidih pada cooking time optimal kemudian ditiriskan. Jumlah padatan yang ada pada air sisa rebusan diukur dengan cara gravimetric.

Selanjutnya dilakukan penelusuran data dan informasi di lapangan tentang peran sagu dalam menjaga lingkungan. Parameter yang dilihat untuk lingkungan adalah kemampuan tanaman sagu sebagai penyerap karbon dan dalam hal menjaga tata air. Data berasal dari data primer dan sekender yang diperoleh dari penelitian terdahulu dan fakta yang terdapat dilapangan. Data yang diperoleh selanjutnya diolah dan dianalisa untuk diungkap kecenderungan kedepan.

\section{HASIL DAN PEMBAHASAN}

\subsection{Sagu sebagai sumber pangan}

Mie merupakan makanan yang sudah populer di negeri ini. Banyak orang cenderung mengkonsumsi mie instan sebagai pengganti nasi. Hasil uji organleptik mie sagu dan mie terigu dengan atribut warna, aroma dan rasa tidak berbeda nyata. Bahkan rasa mie sagu skore nilainya lebih tinggi disbanding mie terigu karena rasanya lebih kenyal. Warna mie terigu lebih tinggi meski secara keseluruhan skore nilai tidak berbeda nyata.

Data mie sagu dan hasil uji penerimaan panelis dibanding mie terigu

Tabel 1. Uji penerimaan oranoleptik mie sagu dan mie terigu dan factor lainnya

\begin{tabular}{|c|l|c|c|}
\hline No & Parameter & Mie sagu & Mie terigu \\
\hline 1 & Warna & $3,5 \mathrm{a}$ & $3,7 \mathrm{a}$ \\
\hline 2 & Aroma & $3,2 \mathrm{~b}$ & $3,3 \mathrm{~b}$ \\
\hline 3 & Rasa & $3,9 \mathrm{c}$ & $3,7 \mathrm{c}$ \\
\hline 4 & $\begin{array}{l}\text { Asal bahan } \\
\text { baku }\end{array}$ & $\begin{array}{c}\text { Dalam } \\
\text { negeri }\end{array}$ & impor \\
\hline 5 & $\begin{array}{l}\text { Kandungan } \\
\text { resistant } \\
\text { starch } \\
\text { (mg/g) }\end{array}$ & $\begin{array}{c}\left.45,26^{*}\right) \\
\left.9,29^{*}\right)\end{array}$ \\
\hline 6 & $\begin{array}{l}\text { Sisi } \\
\text { Ketahanan } \\
\text { pangan }\end{array}$ & $\begin{array}{c}\text { Mendu } \\
\text { kung }\end{array}$ & $\begin{array}{c}\text { Tidak } \\
\text { mendukung }\end{array}$ \\
\hline 7 & $\begin{array}{l}\text { Sisi } \\
\text { Lingkungan }\end{array}$ & $\begin{array}{c}\text { Mendu } \\
\text { kung }\end{array}$ & Tidak terkait \\
\hline 8 & $\begin{array}{l}\text { Devisa } \\
\text { mat }\end{array}$ & $\begin{array}{c}\text { Menhambur } \\
\text { kan }\end{array}$ \\
\hline 9 & $\begin{array}{l}\text { Perekonomie } \\
\text { an nasional }\end{array}$ & $\begin{array}{c}\text { Mendu } \\
\text { kung }\end{array}$ & Menguras \\
\hline
\end{tabular}

*) Data dari Widangnirum, Santosa dan Yuli (2007) 
Bila ditinjau dari Tabel diatas menggambarkan bahwa daya terima panelis yang ditunjukkan dengan penerimaan panca indra seperti warna, aroma dan rasa nilainya tidak berbeda antara mie yang terbuat dari sagu dan mie yang terbuat dari terigu. Secara uji statistic memberi perbedaan tidak nyata. Informasi ini memberi petunjuk bahwa mie sagu dan mie terigu tidak memberi perbedaan dalam penerimaan panelis. Selanjutnya bila ditinjau dari asal bahan baku jelas bahwa sagu berasal dari dalam negeri yang akan mendukung ketahanan pangan nasional. Sedangkan terigu berasal dari impor yang dapat menjadikan Indonesia sangat bergantung pada produk luar negeri dan terjebak dalam jebakan pangan.

Bila ditinjau dari aspek lingkungan dengan menggunakan bahan baku sagu maka lingkungan akan terjaga baik sebagai penyerap karbon maupun menjaga keseimbangan air, sedangkan untuk terigu karena tidak tumbuh di Indonesia tentu tidak berpengaruh langsung

Ditinjau dari ketahanan pangan hadirnya mie sagu ini menjadi salah satu pilihan dari perwujudan bentuk diversifikasi pangan. Hal ini baik untuk menghambat agar konsumsi makanan tidak selalu beras dan terigu. Sagu, yang merupakan bahan baku lokal menjadi salah satu pilihan untuk meningkatkan ketahanan pangan kita agar menjadi lebih kokoh terhadap berbagai "jebakan pangan" seperti mengimpor terigu. Sampai tahun 2010 konsumsi terigu per kapita mencapai $16 \mathrm{~kg} / \mathrm{kap} / \mathrm{th}$ dan ini akan cenderung meningkat terus. Oleh sebab itu tidak heran produksi mie instan di Indonesia terus meningkat dan mencapai 24 milyar bungkus pertahunnya. Beberapa penelitian sebelumnya menunjukkan bahwa pembuatan mie dengan metoda shetting hanya menghasilkan campuran sagu $60 \%$ dan $40 \%$ tepung jagung ${ }^{7}$. Sedangkan Royaningsih dan Pangloli ${ }^{8}$ melaporkan pembuatan mie sagu dengan metoda shetting dimana tepung sagu sebagai campuran terigu maksimal hanya $30 \%$ dimana panelis masih dapat menerima mie yang diujikan. Penelitian yang dilakukan oleh Purwani dkk ${ }^{5}$ bahwa pembuatan mie sagu menggunakan proses adonan bubur sagu kemudian dicetak dapat mencapai bahan baku sagu $100 \%$.

Hasil uji kriteria mie sagu dan mie terigu dengan parameter cooking losses, waktu tanak, disajikan pada Tabel 2.

Parameter waktu tanak dan cooking losses dalam produk mie merupakan parameter penting. Tabel diatas parameter waktu tanak dan cooking losses tidak begitu berbeda nilainya. Artinya bahwa mie sagu yang dihasilkan dapat dikatakan sudah mendekati parameter mie terigu. Oleh sebab itu pengembangan mie sagu sebagai penyediaan pangan menjadi sangat relevan guna mengurangi penggunaan terigu yang harus diimpor.

Tabel 2. Hasil uji kriteria mie sagu dan mie terigu

\begin{tabular}{|c|l|c|c|}
\hline No & Parameter & Mie sagu & Mie terigu \\
\hline 1 & $\begin{array}{l}\text { Cooking } \\
\text { losses }\end{array}$ & $13 \%$ & $11 \%$ \\
\hline 2 & $\begin{array}{l}\text { Waktu } \\
\text { tanak }\end{array}$ & 8 menit & 7 menit \\
\hline
\end{tabular}

Dengan adanya gangguan iklim global yang mengganggu produksi pangan dunia termasuk produksi terigu maka tidak tertutup kemungkinan suatu saat negara produsen terigu akan menahan terigunya dan tidak diekspor ke negara yang membutuhkan seperti Indonesia ini, meski kita memiliki uang untuk membelinya. Kondisi ini tentu akan mengganggu kestabilan suatu negara akibat gangguan pasokan pangannya. Ishizaki ${ }^{9)}$ melaporkan bahwa tanaman sagu memieliki peranan penting dalam penyediaan karbohidrat dengan produktifitas pati 10-15 ton/ha/th, sedangkan pati dari padi hanya 3 ton/ha/th; jagung 5 ton/ha/th, kentang 2.5 ton/ha/th; ubikayu 5-6 ton/ha/th dan ubijalar 5,5 ton/ha/th.

Saat ini mie ini sangat popular di 
masyarakat, baik disantap pagi, siang maupun sore. Belum lagi bila ada bencana alam, mie instan menjadi salah satu pangan favorit untuk keadaan darurat. Dapat dibayangkan bila suatu saat harga terigu internasional meningkat, ketergantungan industri mie kita akan terganggu pasokan terigunya. Oleh karenanya, pengenalan mie sagu ini penting dan perlu sosialisasi lebih luas agar lebih dikenal dan memasyarakat.

Selain dari terigu, mie dapat dibuat dari bahan tepung atau pati lainnya dan salah satunya sagu. Perlu dibedakan istilah tepung dan pati. Yang dimaksud tepung adalah bentuk bubuk putih yang diperoleh dari hancuran biji-bijian. Sedangkan yang dimaksud pati adalah bubuk putih yang berasal dari sari umbi-umbian atau tanaman berbatang. Tanaman sagu (Metroxylon sp) merupakan tanaman asli Indonesia yang berpotensi untuk dikembangkan sebagai pangan alternative dan dapat dibuat miee. terutama di kawasan timur Indonesia. Dari sisi kesehatan, mie sagu memiliki keunggulan dibanding mie terigu karena mengandung resistant starch (RS).

RS adalah fraksi pati tidak tercerna yang secara fisiologis berfungsi seperti serat makanan, sehingga baik bagi kesehatan usus dan sebagai prebiotik. Kadar RS miee sagu sekitar 3-4 kali dari RS dalam miee instan dari terigu. Mengkonsumsi mie sagu juga tidak akan menimbulkan lonjakan kadar glukosa dalam darah sehingga aman bagi penderita diabetes melitus.

Seperti dilaporkan oleh Ega ${ }^{10)}$ bahwa masyarakat yang mengkonsumsi sagu jarang terkena penyakit diabetes. Secara empiris penderita diabetes di Maluku relative kecil terutama di daerah penghasil sagu. Selain itu $\mathrm{Ega}^{10)}$ juga menambahkan bagi mereka yang mengkonsumsi sagu secara teratur, maka pencernaanya menjadi lebih baik karena makanan lebih mudah dicerna oleh bakteri usus.

Oleh sebab itu mie sagu sangat bermanfaat sebagai menu makanan yang menyehatkan. Penelitian yang dilakukan oleh
Sialana ${ }^{11)}$ peneliti dari Unido menyebutkan bahwa mengkonsumsi sagu secara teratur dapat menyehatkan dan tidak menyebabkan perut buncit. Seperti dituturkan oleh Sialana ${ }^{11)}$ sagu menjadi komoditas penting dalam menu makanan masyarakat Ambon karena dengan makan sagu secara ilmiah dapat dijelaskan :

1. Mengandung pati yang tidak dapat dicerna $45 \%$ sehingga akan mengikat racun-racun yang terdapat dalam usus dan mengeluarkan lewat faces

2. Dengan demikian dapat berfungsi untuk membantu pencernakan

3. Secara empiris konsumsi sagu sebaiknya pagi hari karena akan membantu pencernakan

4. MasyarakatMalukuyang mengkonsumsi sagu relative sehat, giginya baik, mata juga baik. Umur 60 th dapat membaca tanpa kaca mata

5. Secara empiris Sekda Propinsi Maluku (Rose Far-Far) setiap hari mengkonsumsi sagu sebagai menu makannya

6. Yang menjadi masalah adalah bahwa ada kesan bahwa masyarakat yang mengkonsumsi karbohidrat selain beras adalah inferior, kelas 2 sehingga memberi pencitraan yang rendah padahal dengan makan sagu secara teratur badan menjadi sehat, kuat dan lingkungan lestari. Biasanya pada areal yang ditumbuhi sagu pasti akan tersedia air. Disamping itu daun sagu juga dapat berfungsi untuk menangkap emisi karbon dan penyedia oksigen. Dengan demikian dapat membantu dampak negatip perubahan iklim global

Keadaan ini menjadi penting bahwa sagu dapat digunakan sebagai pangan fungsional. Bila hipotesa bahwa mengkonsumsi sagu dapat menyehatkan, maka anugerah besar bagi bangsa Indonesia yang oleh Tuhan telah diberikan sagu yang melimpah, yang selain dapat mengenyangkan sekaligus juga menyehatkan. 
Untuk tingkat rasa secara uji organoleptik secara umum mie sagu dapat diterima.

Selain unggul dari sifat fungsionalnya, sagu juga memiliki nilai ekonomi cukup baik. Sebagai gambaran adalah sebagai berikut. Setiap $1 \mathrm{~kg}$ bahan baku sagu akan diperoleh 5 bungkus mie sagu. Harga mie sagu Rp 3000. Berarti pendapatan Rp 15.000. Harga $1 \mathrm{~kg}$ bahan baku sagu Rp 2000, biaya proses dan tenaga kerja Rp 1000, biaya kemasan Rp 200 , biaya pemasaran per bungkus Rp 800 . Berarti untuk biaya $1 \mathrm{~kg}$ mie sagu adalah Rp 3000. Dengan demikian margin pembuatan mie sagu setiap $\mathrm{kg}$ adalah Rp 12000. Dengan pembuatan mie sagu ini akan diperoleh nilai tambah 5-6 kali lipat harga bahan baku. Bila dibanding dengan mie telor di pasaran pada tahun 2010 harganya mencapai Rp 5000,, harga mie sagu ini sangat kompetitif dan menggunakan bahan baku lokal.

Untuk lebih mendorong berkembangnya mie sagu maka penyediaan bahan baku pati sagu menjadi keharusan agar usaha mie sagu terus berkelanjutan. Oleh sebab itu pengelolaan tanaman sagu secara agribisnis yang melibatkan input, proses dan out put perlu disiapkan. Sebagai input adalah bahan baku batang sagu yang diperoleh dari kebun sagu, proses adalah cara mengeluarkan pati sagu yang dilakukan dengan cara ekstraksi dan out put adalah hasil pati sagu. Untuk menggambarkan proses tersebut alur bagannya disajikan pada Gambar 1

Pengelolaan sagu dapat dilakukan dengan beberapa model

Memproduksi pati

1. Melalui unit ekstraksi kecil dan terdapat penampung untuk memproses lebih lanjut menjadi pati yang berkualitas.

2. Setiap unit ekstraksi memieliki peralatan ekstraktor dan disiapkan areal sagu seluas 40 ha dengan tenaga kerja terdiri dari pemasok, pemroses berkisar 5 sampai 8 orang

3. Luasan kebun sagu skala ekonomis adalah 40 ha dengan perhitungan sebagai berikut :
Bentuk usahanya dilakukan seperti bagan pada Gambar 2.

Asumsi yang digunakan

- $\quad$ Setiap kelompok terdiri dari 4-5 orang untuk mengektraksi sagu.

- $\quad$ Rincian tersebut 2 orang menebang sagu dan setiap hari 2 pohon sagu dengan panjang $6 \mathrm{~m}$ dan dimeter 40 $\mathrm{cm}$. Selanjutnya pohon sagu dipotong menjadi $1 \mathrm{~m}$ sehingga akan diperoleh 12 potong sagu @ 1 m panjang.

- $\quad$ Seorang lagi bertugas mengangkut sagu ke tempat ekstraktor. Seorang bertugas mengupas dan membelah dan seorang bertugas memarut sagu.

- Dengan kapasitas proses setiap hari 2 pohon. Berat $1 \mathrm{~m}$ batang sagu $150 \mathrm{~kg}$ sehingga 12 batang beratnya $1800 \mathrm{~kg}$.

- Kulit $20 \%$ sehingga berat empulur 1800 $\mathrm{kg}-360 \mathrm{~kg}=1420 \mathrm{~kg}$

- $\quad$ Rendemen pati sagu $20 \%$ sehingga akan diperoleh pati sagu $0.2 \times 1420 \mathrm{~kg}$ $=284 \mathrm{~kg}$ atau diambil rata-rata $250 \mathrm{~kg}$ pati sagu

- Bila setiap hari butuh 2 pohon sagu dan sebulan 25 hari kerja maka setiap bulan butuh bahan baku sagu 50 pohon. Bila setiap ha berisi 10 pohon yang siap tebang maka setiap bulan butuh lahan 5 ha per kelompok yang terdiri dari 5 orang.

- Bila dalam suatu kawasan yang terdiri dari beberapa desa dan terdiri 40 kelompok maka diperlukan lahan sagu 200 ha

- Dari 40 kelompok tersebut akan diperoleh pati sagu kasar sebanyak $250 \mathrm{~kg} \mathrm{x} 40=10.000 \mathrm{~kg}$ per hari atau 10 ton per hari

- $\quad$ Setiap bulan akan menghasilkan pati sagu 10 ton $\times 25$ hari $=250$ ton

- Dengan adanya sagu yang dikelola dalam kawasan tersebut maka akan diberdayakan masyarakat sebanyak 5 orng $\times 40=200$ orang.

Selanjutnya terdapat industri pengolah sagu kasar yang membutuhkan tenaga kerja paling kurang 10 orang sehingga 
akan menciptakan peluang tenaga kerja 210 orang

- Dari kegiatan tersebut akan terwujud kegiatan lain yang menunjang kegiatan ini. Bila dari setiap kelompok dapat mendorong terbukanya warung yang menampung 2 orang maka akan ada tambahan peluang kerja 2 xs $40=80$ orang.

- Disisi lain akan memicu terbukanya kegiatan transpotasi, dan kegiatan ekonomi lainnya.

Perkiraan pendapatan petani secara kasar dijelaskan sebagai berikut:

Setiap hari akan dihasilkan pati 10 ton dan bila harga $1 \mathrm{~kg}$ sagu Rp 1500 maka penghasilan dari sagu adalah $10.000 \times \mathrm{Rp}$ $1500=\operatorname{Rp} 15.000 .000$

Pengadaan bahan baku sagu setiap hari 40 x 2 pohon=80 pohon @ Rp 50.000 $=$ Rp 4.000.000. Selanjutnya biaya proses (air , listrik, tenaga kerja over head dll) = $40 \times \operatorname{Rp} 200.000=\operatorname{Rp~8.000.000.~Dengan~}$ demiekian total pengeluaran Rp 12.00.000. Dengan perhitungan tersebut setiap hari akan diperoleh margin Rp 15.000.000 Rp 12.000.000 = Rp 3.000.000 . Rincian pengeluaran untuk iap kelompok sebesar Rp 200.000 ( Tenaga Kerja 5 orang @ 25.000 =Rp 125.000, Bahan bakar 8 liter @ 7500 $=$ Rp 60.000, Air dan overhead Rp 15.000). Dengan perhitungan ini pekerja setiap hari akan mendapat Rp 25.000 dan pemilik pohon sagu Rp 50.000 .

Dengan adannya kegiatan pengolahan sagu tersebut akan dapat menampung tenaga kerja dan diharapkan dapat menggerakan perekonomian yang lain. Agar nilai tambah sagu meningkat dan harga bahan baku pohon sagu juga akan meningkat maka produk yang dihasilkan tidak hanya pati sagu tetapi dalam bentuk produk sohun ataupun pangan fungsional yang berfungsi sebagai pangan kesehatan.

Konsep ini masih dalam perencanaan dan perlu adanya verifikasi di lapangan untuk mendapatkan data yang riil dan berlaku saat ini. Oleh karena itu verivikasi data yang diasumsikan perlu dilakukan dan perlu menangkap keinginan masyarakat saat ini, sagu ini akan dibiarkan begitu saja atau dapat dimaksimalkan pemanfaatannya.

Seiring dengan perkembangan jaman dan mendukung pasokan bahan baku ke industri mie sagu maka proses pemasaran pati sagu akan berubah dalam bentuk sagu kering dan bukan sagu tumang lagi. Yang disebut sagu tumang adalah pati sagu basah dengan kemasan daun sagu dengan berat kemasan sekitar $10 \mathrm{~kg}$. Dengan pasokan sagu kering maka penyimpanan bahan baku dan sistem pengangkutannya lebih praktis. Pasokan bahan baku sagu menjadi sangat penting guna memenuhi kebutuhan industri mie sagu. Dengan demikian sistem pasokan bahan pati sagu harus dioptimalkan agar keberadaan industri mie sagu dan produk lainnya tetap mendapat pasokan bahan baku.

Guna mewujudkan peran sagu sebagai penyedia bahan pangan yang terkait dengan ketahanan pangan, dan upaya pengelolaan sumber daya alam secara lestari dan penciptaan lapangan kerja maka perlu dibuat suatu model percontohan pengelolaan hutan sagu menjadi kebun sagu dan dilengkapi dengan unit pengolahannya baik untuk menghasilkan pati sagu atau bahkan sampai ke produk hilirnya. Dengan adanya percontohan ini nantinya dapat dijadikan model yang secara spesifik dapat diterapkan di daerah penghasil safu. Bentuk model pengelolaan sagu yang sudah berjalan dengan baik yang menghasilkan pati sagu adalah berdirinya kilang sagu di Selat Panjang propinsi Riau. Usaha ini sudah berjalan dengan baik dan dapat membantu perekonomian kabupaten Bengkalis dimana Selat Panjang berada. Dengan luasan hanya 30 ribu ha dan jumlah kilang (pengolah sagu) sekitar 92 dapat menghasilkan pati sagu sebanyak 60.000 ton setiap tahun. Bila setiap kg pati sagu dikenakan restribusi daerah sebesar Rp 100 maka setiap tahun Pendapatan ASli Daerah (PAD) dari sagu 
saja akan diperoleh sebesar $60.000 .000 \mathrm{x}$ Rp $100=\operatorname{Rp~6.000.000.000~atau~sebesar~}$ 6 milyar rupiah ${ }^{12}$. Dari sisi jumlah mungkin sedikit tetapi dibanding bahan tambang yang tidak renewable maka dalam pengelolaan sagu akan lebih lestari ${ }^{12)}$

\subsection{Peran Sagu dalam Pengendalian kualitas Lingkungan}

Ditinjau dari aspek lingkungan tanaman sagu dapat menjaga tata air di sekitarnya. Beberapa fakta di lapanan menunjukkan bahwa banyak di daerah pedesaan terdapat sumber-sumber air dalam bentuk pancuran dan disekitarnya pasti terdapat tanaman sagu. Meski fakta ini belum dapat dijelaskan secara ilmiah oleh para ahli namun fenomena tersebut dapat memberi gambaran secara teoritis bahwa tanaman sagu dapat menjaga tata air di daerah sekitarnya. Peran sagu sebagai menjaga tata air telah di prediksi Stanton ${ }^{13)}$ yang menjelaskan bahwa tanaman sagu dapat menjaga tata air - Selanjutnya penelitian yang dilakukan oleh Sitaniapesy ${ }^{14)}$ menjelaskan bahwa di dalam tanah perakaran tanaman sagu akan menyerap air dan haran mieneral. Pada daerah tergenang peranakan tanaman sagu akan terpusat pada lapisan permukaan tanah dan bahkan pada ketinggian $1 \mathrm{~m}$ batang di permukaan dipenuhi akar dan sering muncul anakan sagu.

Selanjutnya dalam pertumbuhan tanaman sagu Haska dkk ${ }^{15}$ melakukan penelitian tentang kemampuan penyerapan $\mathrm{CO}_{2}$ dimana untuk tanaman sagu memieliki nilai 240 ton $\mathrm{CO}_{2} /$ ha/th, jagung 216 ton $\mathrm{CO}_{2} /$ ha/th, padi 81 ton $\mathrm{CO}_{2} /$ ha/th; ubi kayu ton $\mathrm{CO}_{2} /$ ha/th, tebu 225 ton $\mathrm{CO}_{2} /$ ha/th dan ubi jalar 88 ton $\mathrm{CO}_{2} /$ ha/th. Berdasarkan angkaangka tersebut tanaman sagu memiliki lebihan dibanding tanaman padi maupun jagung. Disamping itu dalam menghadapi perubahan iklim global dimana terjadi pergeseran musim yang ekstrim tanaman sagu relative lebih tahan dibanding tanaman musiman lainnya seperti jagung atau padi.
Terjadinya banjir dan kekeringan tanaman penghasil karbohidrat dari biji-bijian sangat rentan terhadap kekeringan dan banjir. Lain halnya untuk tanaman sagu relative tahan baik terjadi kekeringan maupun banjir akan berdiri kokoh karena karena akarnya tertancap ke dalam dan memiliki cadangan makanan dan air yang memadai.

Dipihak lain dengan dikenalkannya makanan sagu berbentuk mie yang dapat diterima oleh masyarakat secara umum dan penyediaan bahan baku yang kontinyu dan tersedia setiap saat menjadi sangat mungkin sagu sebagai penyangga ketahanan pangan.

Oleh karena itu tanaman sagu dapat menjadi sebagai penyedia pangan dan secara lingkungan tanaman sagu sangat bermanfaat terutama untuk di tanam di daerah yang banyak polusinya karena dapat menyerap karbondioksida paling tinggi dibanding tanaman lain. Oleh sebab itu pernyataan Prof Stanton tahun ${ }^{16)}$ mulai dapat dijelaskan sebutan tanaman sagu merupakan tanaman kuno tetapi sekaligus tanaman modern baik sebagai penyedia bahan pangan sekaligus sebagai tanaman penjaga lingkungan. Ditinjau dari keberlanjutan tanaman sagu sudah lama tumbuh di negeri ini dan akan lebih tahan terhadap perubahan iklim yang belakangan ini mengancam produksi biji- bijian kita.

\section{KESIMPULAN DAN SARAN}

Berdasarkan uraian diatas maka dapat disimpulkan beberapa hal sebagai berikut :

1. Pemanfaatan sagu sebagai pembuat mie memiliki sifat yang dapat diterima oleh panelis dan memiliki peluang untuk dikembangkan upaya sebagai subsitusi terigu.

2. Sifat mie sagu yang diuji secara organoleptik ke panelis secara umum dapat diterima dan tidak berbeda dengan mie terigu

3. Guna mengembangkan mie sagu perlu ddukung dengan pasokan bahan baku pati sagu dalam bentuk perkebunan sagu 
4. Mie yang terbuat dari pati sagu memiliki keunggulan dalam kandungan resistant starch yang bermanfaat bagi kesehatan

5. Pengembangan tanaman sagu dapat bersifat sebagai penyedia pati sagu yang digunakan untuk diversifikasi dan sekaligus berfungsi sebagai penjaga lingkungan

Untuk itu sebagai saran maka tanaman sagu yang sudah hampir punah ini perlu dijaga bahkan dikembangkan karena sangat berfungsi sebagai penyedia bahan pangan dalam bentuk karbohidrat dan dan dapat menjaga lingkungan baik sebagai penjaga tata air maupun sebagai penyerap racun dari industri.

Agar mie sagu lebih dikenal maka perlu adanya sosialisasi terus menerus ke areal yang lebih luas dalam rangka implementasi Per Pres No 22 Tahun 2009 tentang pemanfaatan bahan baku lokal ${ }^{17}$.

\section{DAFTAR PUSTAKA}

1. Anonimous. 2011. Gagal Panen di Berbagai Daerah. Harian Kompas 15 Januari 2011

2. Peraturan Presiden No 22 Tahun 2009 tentang Kebijakan Pemanfaatan Bahan Baku Lokal.

3. Haryanto dan Pangloli. 1992. Potensi dan Pengolahan Sagu. Kanisius. Yogyakarta.

4. Flach. M. 1997. Sago Palm Metroxylon Sagu Rottb. International Plant Generic Resources Institute. Rome. Promoting The Conservation and The use of under utilized ang neglected Crops.

5. Widaningrum, Santosa dan Endang Yuli Purwani. 2007. Penelitian Pengaruh Suhu Pemeraman Terhadap Kualitas Mie Sagu dan Kadar Resistant Starch (RS). Prosiding Seminar Nasional
6. Purwani, E. Y., Y Setiawati, H. Setianto, S.J. Munarso, N. Richana dan Widaningrum. 2004. Utilization of Sago Starch For Transparant Noodle in Indonesia. Prosiding Seminar Nasional Peningkatan Daya Saing Pangan Tradisonal. Balai Besar Penelitian dan Pengembangan Pascapanen Pertanian. Badan Penelitian dan Pengembangan Pertanian.

7. Datu D. Y. R, M. Bilang dan S. D. Amrulla (2005) Mempelajari Pengolahan Miee Dari Campuran Tepung Sagu Dan Tepung Jagung. Teknologi Hasil Pertanian Universitas Hasanuddin www.unhas.ac.id/tekpert

8. Royaningsih S dan Pangloli.1988. Pembuatan mie Basah dari Campuran Terigu dan Pati Sagu. Prosiding Seminar Penelitian Pasca Panen Pertanian. Badan Penelitian dan Pengembangan Pertanian. Departemen Pertanian. Jakarta

9. Ishizaki, A. 1996. Sago: The Future Source of Food and Feed. Closing Remark: In Christine Jose and Aslim Rasyid (eds). Proc.Of the Sixth. Itl. Sago Symp. Pekanbaru. Indonesia.

10. Ega . 2009. Manfaat Mengkonsumsi Sagu bagi Masyarakat Maluku. Komunikasi Pribadi

11. Sialana.A.S.,2007. Teknologi Sederhana Produksi Tepung Sagu Kering dan Preferensi Kosumen Terhadap Produk Sagu. Sebuah Kajian. Makalah Seminar Nasional Sagi di Ambon 29-30 Oktober 2007. BPTP. Maluku. Ambon

12. Haryanto. B. 2007. Perencanaan Pengembangan Sagu di Kabupaten Lingga Propinsi Kepulauan Riau. Prosiding Lokakarya Pengembangan 
Sagu di Indonesia. Batam 25-27 Juli 2007. Pusat Penelitian dan Pengembangan Perkebunan. Badan Penelitian dan Pengembangan Pertanian. Bogor.

13. Stanton R, 1996. The Role of AgroForestry and Non Cereal Agricultural in Meeting Future Staple Carbohidrate Food Need of The People of Souteast Asia.Sago: The Future Source Of Food And Feed. Sixth International Sago Symposium. Editor : Jose Christine and Aslim Rasyad. Riau University Training Center. Pekanbaru. Riau. Indonesia

14. Sitaniapesy (1996). Sagu :Suatu Tinjauan Ekologi. Prosiding Nasional Sagu III. Potensi Sagu Dalam Usaha Penembangan Agribisnis Di Wilayah
Lahan Basah. Unri Riau-Pemda Tk I Riau dan BPPT. Pekabaru. Riau

15. Haska N, H. Pranamuda dan Y. Yamamoto. 2007. Karakteristik Fotosintesis dan Serapan $\mathrm{CO} 2$ dari Palma Sagu (Metroxylon sagu, Rottb). Prosiding Lokakarya Pengembangan Sagu di Indonesia. Pusat Penelitian dan Pengembangan Perkebunan. Badan Penelitian dan Pengembangan Pertanian. Bogor.

16. Stanton W.R. 1979. Sago and Enviromental. Di dalam Stanton W.R. and M. Flach (edited) Sago The Equatorial Swamp as Natural Resource. Proceeding of the second International Sago Symposium. Kualalumpur. Malaysia.

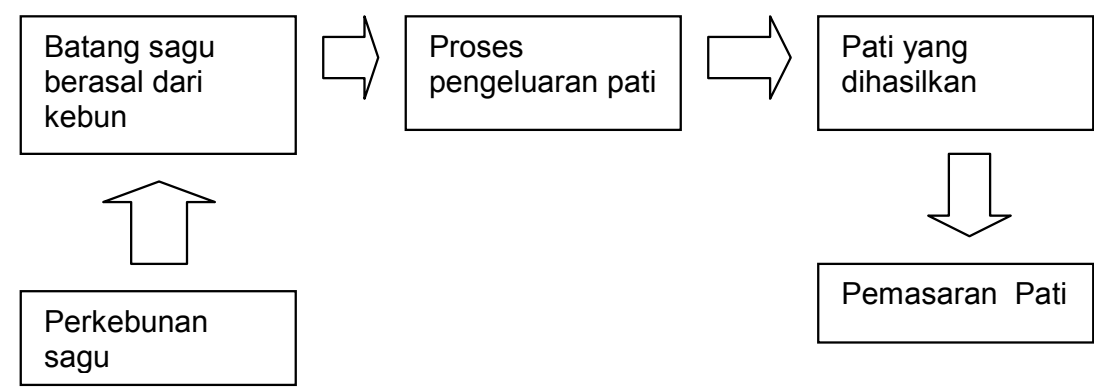

Gambar 1. input dan output proses pengelolaan sagu

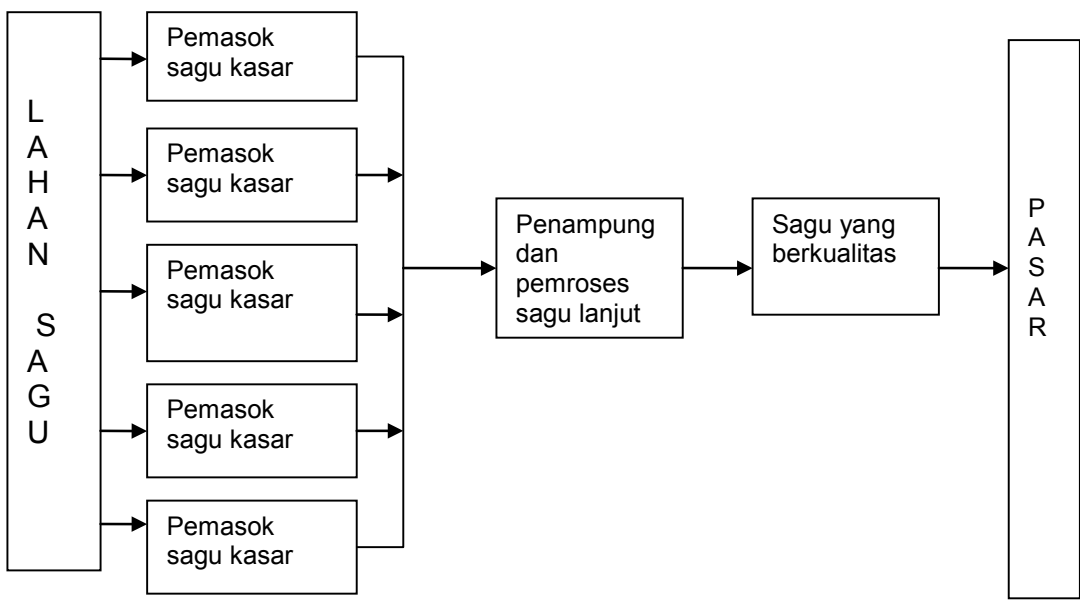

Gambar 2. Bentuk pengelolaan sagu 